\title{
RESPON SISWA TERHADAP PENGEMBANGAN MEDIA MODEL KEMAGNETAN BUMI
}

\author{
Muh. Husnul Fikri' ${ }^{1}$, Aris Doyan' ${ }^{2}$, Ahmad Harjono ${ }^{3}$, \\ Program Studi Magister Pendidikan IPA Program Pascasarjana Universitas Mataram ${ }^{123}$ \\ SMP Nurul Islam Hikmah ${ }^{1}$ \\ Muh.husnulfikti@gmail.com, arisdoyan@yahoo.co.id, ahmad_harjono@yahoo.co.id
}

\begin{abstract}
ABSTRAK
Penelitian ini bertujuan untuk mengembangkan media pembelajaran materi IPA Kemagnetan pada tingkat SMP berbentuk media Model Kemagnetan Bumi (MKB). Penelitian dilakukan dengan menggunakan pendekatan Research and Development menurut Borg \& Gall yang dimodifikasi oleh Sukmadinata menjadi 3 tahap yaitu studi pendahuluan, uji coba model dan uji produk.Uji coba model dilakukan dalam dua tahap yaitu uji coba terbatas yang dilakukan di SMK Islam Nurul Hikmah Langko Lombok Barat dan uji coba pada kalangan yang lebih luas di SMPN 3 Lingsar Lombok Barat. Pada tahap uji coba skala lebih luas didapatkan karakteristik media MKB. Diakhir tahap uji coba skala lebih luas dilakukan penyebaran angket untuk mendapatkan respon siswa terhadap pengembangan media MKB pada 20 siswa. Siswa memberikan tanggapan positif terhadap pengembangan media MKB.
\end{abstract}

Kata kunci : Media Model Kemagnetan Bumi, Respon Siswa.

\begin{abstract}
This study aims to develop instructional media materials science magnetism at the junior level Models Earth Magnetism (MKB)media. The study was conducted by using the approach of Research and Development by Borg \& Gall modified by Sukmadinata into 3 stages: a preliminary study, test models and test the product. Modeling exercise carried out in two stages. Limited test phase conducted at SMK Islam Nurul Hikmah Langko West Lombok and wider scale trials as well as the testing phase at SMPN 3 Lingsar. Of wider scale pilot phase characteristics obtained MKB media. At the end of the pilot phase conducted a broader scale questionnaire to get students' response in the development of MKB media at 20 students. Students responded positively to the development of MKB media.
\end{abstract}

Keywords : Media Model of Earth Magnetism, Student Response.

\section{Pendahuluan}

Penelitian dan pengembangan dapat diartikan sebagai kegiatan pengumpulan data, pengolahan, analisis dan penyajian data yang dilakukan secara sistematis dan obyektif yang disertai dengan kegiatan pengembangan sebuah produk untuk memecahkan suatu 
persoalan yang dihadapi. Produk yang dihasilkan dalam penelitian dan pengembangan dalam dunia pendidikan dapat berupa materi pelatihan guru, materi ajar, seperangkat tujuan perilaku, materi media, dan sistem-sistem manajemen (Emzir, 2010).

Penelitan dan pengembangan ini berdasar dari hasil ujian nasional tahun pelajaran 2009-2010 didapatkan Standar Kompetensi Kelulusan (SKL) terendah untuk mata pelajaran IPA propinsi Nusa Tenggara Barat adalah menentukan kutub-kutub sifat pada magnet buatan dengan gosok/aliri listrik/ dan induksi jika dekat, dengan nilai rata-rata tahun 2009-2010 adalah 3,64 pada soal paket A. Melalui studi pendahuluan diawali dengan observasi bahwa pengembangan media tiga dimensi maupun pengembangan dalam bentuk media yang lain baik pada materi kemagnetan maupun pada materi yang lain sangat jarang dilakukan sedangkan pemberian pengalaman langsung kepada siswa bertumpu pada kit praktikum bantuan pemerintah.

Merujuk pada buku pedoman operasional kit listrik magnet menunjukan bahwa untuk praktikum materi kemagnetan yang tersedia hanya untuk mendeteksi sifat kemagnetan bahan dan percobaan Oersted. Dua praktikum tersebut tidak memenuhi beberapa konsep penting dalam kemagnetan seperti membuat magnet dengan konduksi, induksi dan elektromagnet, percobaan kemagnetan bumi, dan aplikasi magnet dalam produk teknologi. Kekurangan tersebut menimbulkan asumsi kuat peneliti sebagai penyebab rendahnya nilai Ujian Nasional pada standar kompetensi kelulusan kemagnetan

Kehadiran media dalam proses pembelajaran menjadi penting agar dapat memfasilitasi tujuan pembelajaran fisika yang salah satunya dengan metode eksperimen. Sebagaimana yang diungkapkan oleh Djamarah (2002) bahwa pembelajaran eksperimen merupakan cara penyajian pelajaran di mana siswa melakukan percobaan dengan mengalami dan membuktikan sendiri sesuatu yang dipelajari sehingga dapat membentuk siswa lebih percaya atas kebenaran atau kesimpulan berdasarkan percobaannya disamping dapat membina siswa untuk membuat terobosan-terobosan baru dengan penemuan dan percobaannya.

Media pembelajaran kemagnetan yang kemudian disebut media Model Kemagnetan Bumi (MKB) diharapkan dapat membantu siswa dalam memahami kemagnetan seperti kemagnetan bahan, membuat magnet dengan menggosok, induksi dan elektromagnet, kutub magnet, medan magnet di sekitar kawat berarus listrik dan beberapa aplikasi dari magnet.

Pada tahap penelitian dan pengembangan media MKB yang dilakukan diperoleh karakteristik media MKB dan data respon siswa. Respon siswa tersebut merupakan 
tanggapan siswa terhadap media yang digunakan dalam pembelajaran fisika kemagnetan. Seperti halnya hasil penelitian Fajaruddin (2012) tentang pengembangan media fisika untuk materi listrik arus searah mendapat tanggapan baik oleh siswa.

Bertolak dari paparan tersebut sasaran penelitian ini adalah untuk mengetahui karakteristik media MKB dan respons siswa terhadap pengembangan media MKB pada pembelajaran kemagnetan pada tingkat sekolah menengah pertama.

\section{Metode Penelitian}

Penelitian dan pengembangan media MKB untuk materi IPA kemagnetan diadaptasi dari research and development. Dalam penelitian ini, peneliti mengembangkan media MKB sampai pada uji coba model yang meliputi Uji coba skala terbatas, revisi produk berdasarkan uji coba terbatas, uji coba skala lebih luas dan perbaikan hasil uji coba skala luas.

Respon siswa dan guru diperoleh melalui instrument respon guru dan siswa yang disebarkan dalam tahap uji coba terbatas, uji coba skala lebih luas, dan tahap pengujian. Sampel penelitian untuk tingkat siswa dipilih dengan menggunakan metode simple random sampling, dengan melibatkan 7 siswa SMU sederajat pada tahap uji coba skala terbatas, 20 siswa SMK pada tahap uji coba skala lebih luas.

Data respon siswa dan guru diperoleh dalam bentuk data kualitatif, selanjutnya dikonversikan dalam bentuk data kuantitatif berdasarkan tanggapan responden dengan menggunkan pilihan jawaban respon skala empat, yaitu: Sangat Setuju (SS) memperoleh skor 4, Setuju (S) memperoleh skor 3, Tidak Setuju (TS) memperoleh skor 2, dan Sangat Tidak Setuju (STS) memperoleh skor 1 (Widoyoko, 2012). Berdasarkan skor data yang diperoleh, selanjutnya diolah menggunakan statistik deskriptif yaitu dengan menghitung rata-rata dari jawaban yang diberikan kemudian dinyatakan dalam bentuk persentase dari setiap pernyataan (Gunawan, 2011).

\section{Karakteristik Media MKB}

Pengembangan media MKB ditujukan dalam rangka menyampaikan konsep-konsep kemagnetan yang diintergrasikan dalam proses pembelajaran kemagnetan. Untuk mendukung pencapaian tersebut, media MKB dilengkapi dengan fitur-fitur yang dapat dimanipulasi siswa melalui learning by doing sehingga dapat memberikan gambaran riil dari konsep-konsep kemagnetan. Media MKB yang dikembangkan juga dilengkapi dengan lembar kegiatan siswa dalam bentuk lembar kerja sebagai penuntun siswa untuk 
memahami konsep yang dipelajari melalui media MKB.

Melalui tahap uji coba skala kecil dan uji coba skala luas, karakteristik media MKB yang dikembangkan sebagai media pembelajaran, diharapkan memberikan pengaruh yang signifikan terhadap hasil belajar siswa karena media MKB sebagai media riil relevan dengan materi kemagnetan. Melalui pembelajaran dengan media riil siswa akan lebih mudah mengingat dan menerapkan konsep yang dipelajari (Heinich, et all. 2002).

Implementasi media MKB dalam pembelajaran dapat menciptakan interaksi siswa secara langsung melalui proses manipulasi media MKB. Konsep-konsep kemagnetan yang ditampilkan media MKB dalam bentuk riil membantu siswa dalam proses berpikir dalam memahami konsep yang dipelajari. Hal ini sesuai dengan pendekatan teori pengembangan media MKB yang dikemukakan Piaget seperti yang disitir Hassard \& Dias (2009) bahwa pengalaman tentang hal-hal yang konkret sangat penting dalam membangun cara berpikir seseorang.

Pembelajaran dengan media MKB secara garis besar terbagi menjadi 4 praktikum menuntut keaktipan siswa dalam bereksperimen dan memberikan ruang bagi siswa untuk memanipulasi berbagai variabel yang ada. Pada praktikum membuat magnet siswa dapat memanipulasi media MKB dengan mengganti jumlah lilitan untuk mengetahuai kualitas medan magnet yang dihasilkan, manipulasi nilai sumber tegangan untuk mendapatkan kekuatan medan magnet yang berbeda-beda, dan manipulasi arah polaritas tegangan terhadap perbedaan kutub magnet yang dihasilkan untuk membuktikan aturan tangan kanan.

Praktikum kemagnetan bumi, siswa dapat memanipulasi posisi magnet jarum yang berfungsi sebagai kompas dan melihat pengaruhnya pada besar sudut inklinasi dan deklinasi.Siswa dapat mengamati dengan jelas perilaku kompas yang tergantung bebas ketika berada di katulistiwa, daerah kutub atau daerah manapun pada peta. Siswa juga dapat memahami perbedaan antara kutub medan magnet bumi dengan kutub geografis bumi.Pada praktikum percobaan Oersted siswa dapat memanipulasi sumber tegangan untuk mempelajari besar simpangan kompas dan lebih mudah dipahami dengan manipulasi polaritas tegangan konduktor.

\section{Hasil Penelitian dan Pembahasan}

Tahap pengembangan yang meliputi tahap perencanaan media MKB, realisasi produk awal media MKB , uji coba skala terbatas dan perbaikannya, uji coba lebih luas, evaluasi dan penyempurnaan. 
Pada tahap realisasi produk awal dihasilkan media MKB yang dapat digunakan untuk melaksanakan 10 praktikum materi kemagnetan yang terbagi dalam 4 bagian pokok uaitu praktikum kemagnetan bahan, praktikum cara membuat magnet, praktikum kemagnetan bumi dan praktikum hokum Oersted. Model media MKB yang dikembangkan didukung dengan Lembar Kerja Siswa (LKS) sebagai panduan siswa melaksanakan kegiatan pembelajaran menggunakan media MKB dan Rencana Pelaksanaan Pembelajaran (RPP) disusun sebagai pedoman pengajaran dalam menyampaikan materi kemagnetan menggunakan media MKB.Data rancangan awal model Kemagnetan bumi ditampilkan pada tabel 1 .

Tabel 1:Rancanganawal model Media Kemagnetan Bumi (MKB) untuk uji coba skala terbatas

\begin{tabular}{|c|c|}
\hline Unit & Penjelasan \\
\hline Alat dan Bahan & $\begin{array}{l}\text { - } \text { Travo } 3 \mathrm{~A} \\
\text { - } \\
\text { - } \text { Kiode Bridge } 5 \mathrm{~A} \\
\text { - } \text { Kesasitor } 5500 \mu \mathrm{F} / 55 \mathrm{~V} \\
\text { - } \mathrm{LED} \\
\text { - Saklar toggle, saklar rotary } \\
\text { - Kawat lilitan } 0,5 \mathrm{~mm} \\
\text { - } \text { Besi lunak } 14 \mathrm{~mm} \\
\text { - Stop kontak audio, male-female } \\
\text { - Saklar push } 16 \text { pin } \\
\text { - Stainless steel (jarum kasur) } \\
\text { - Kabel, isolasi, benang dll } \\
\text { - } \text { Rangka (besi + tripleks) }\end{array}$ \\
\hline Materi praktikum & $\begin{array}{l}\text { - Membuat magnet dengan elektromagnet } \\
\text { - Mengetahui sifat-sifat kutub magnet } \\
\text { - Mengetahui benda-benda yang dapat ditarik oleh magnet } \\
\text { - Membuat magnet dengan cara menggosok } \\
\text { - Membuat magnet secara induksi } \\
\text { - Memahami medan magnet I } \\
\text { - Memahami medan magnet II } \\
\text { - Memahami konsep kemagnetan bumi } \\
\text { - Memahami konsep hukum Oersted } \\
\text { - Memahami prinsip kerja katrol listrik }\end{array}$ \\
\hline Instrumen pendukung & $\begin{array}{l}\text { - Panduan penggunaan media } \\
\text { - Rencana Pelaksanaan Pembelajaran (RPP) } \\
\text { - Lembar Kerja Siswa (LKS) } \\
\text { - Evaluasi kognitif } \\
\text { - Evaluasi psikomotor } \\
\text { - Lembar angket respons siswa } \\
\end{array}$ \\
\hline Lembar Kerja Siswa & $\begin{array}{l}\text { - Berisi ringkasan materi yang disusun sesuai dengan materi praktikum yang akan } \\
\text { dilakukan siswa. Rancangannya dibuat untuk mengarahkan siswa mendapatkan } \\
\text { konsep kemagnetan baik secara berkelompok maupun individu, setelah } \\
\text { mendapatkan penjelasan dan demonstrasi dari guru mata pelajaran. }\end{array}$ \\
\hline Evaluasi & $\begin{array}{l}\text { - Disusun untuk mengevaluasi sejauh mana tingkat penguasaan siswa terhadap } \\
\text { materi dan percobaan dengan media yang sudah dilakukan. Evaluasi kognitif } \\
\text { berbentuk pilihan ganda dengan } 4 \text { opsi pilihan dan evaluasi psikomotor berbentuk } \\
\text { lembar observasi olehguru. }\end{array}$ \\
\hline
\end{tabular}


Media MKB yang sudah terealisasi selanjutnya dilakukan uji coba skala terbatas Sementara itu pada tahap pengujian meliputi tahap uji coba pada kelas eksperimen untuk mengetahui pengaruh media MKB yang diintegrasikan dengan pembelajaran didalam kelas terhadap hasil belajar siswa.

Data respon siswa pada tahap uji coba terbatas diperoleh dengan melibatkan 7 siswa dari SMK Islam Nurul Hikmah Lombok Barat yang telah mendapatkan materi kemagnetan. Pemilihan sampel ini bertujuan untuk memberikan gambaran tentang media MKB dan perangkat pendukungnya pada tahap awal. Pengetahuan awal siswa yang diperoleh melalui pembelajaran kemagnetan sebelumnya diharapkan dapat memberikan masukan dalam bentuk penilaian untuk mengevaluasi model MTDK yang dikembangkan. Data respon siswa pada tahap uji coba skala terbatas dari masing-masing indikator ditampilkan pada tabel 2 .

Tabel 2: Tanggapan siswa terhadap media MKB pada Uji coba Terbatas.

\begin{tabular}{|l|l|l|l|l|}
\hline \multicolumn{2}{|c|}{ PERNYATAAN } & \multicolumn{3}{c|}{ SKOR } \\
\cline { 2 - 5 } & \multicolumn{1}{|c|}{ SS } & \multicolumn{1}{c|}{ SS } & \multicolumn{1}{c|}{ STS } \\
\hline Belajar sains fisika dengan media tiga dimensi MKB menyenangkan & 4 & 3 & 0 & 0 \\
\hline Media MKB cukup menarik & 2 & 5 & 0 & 0 \\
\hline Media MKB mudah digunakan & 0 & 4 & 3 & 0 \\
\hline Petunjukkan penggunaan media MKB mudah dipahami & 0 & 3 & 4 & 0 \\
\hline $\begin{array}{l}\text { Dengan media MKB, materi pembelajaran yang berisi konsep-konsep } \\
\text { kemagnetan lebih mudah dipahami }\end{array}$ & 1 & 5 & 1 & 0 \\
\hline $\begin{array}{l}\text { Dengan media MKB, kaidah dan hukum fisika yang berkaitan dengan } \\
\text { kemagnetan mudah dipahami }\end{array}$ & 4 & 3 & 0 & 0 \\
\hline Pembelajaran sains dengan media MKB mendorong rasa ingin tahu siswa & 2 & 5 & 0 & 0 \\
\hline $\begin{array}{l}\text { Memahami materi-materi yang bersifat abstrak (tidak nyata) menjadi lebih } \\
\text { mudah dipahami setelah menggunakan media MKB. }\end{array}$ & 2 & 3 & 2 & 0 \\
\hline $\begin{array}{l}\text { Media MKB memberikan kesempatan yang luas untuk mencoba melakukan } \\
\text { analisa dan membuat perkiraan/hipotesis }\end{array}$ & 0 & 5 & 2 & 0 \\
\hline $\begin{array}{l}\text { Wawasan tentang kemagnetan menjadi bertambah luas sejak pembelajaran } \\
\text { dengan media MKB. }\end{array}$ & 3 & 4 & 0 & 0 \\
\hline
\end{tabular}

Pada aspek kemudahan penggunaan media, $57 \%$ siswa menyatakan setuju dan 43 $\%$ siswamenyatakan tidak setuju. Munculnya penilaian siswa pada taraf kurang mudah digunakan karena terletak pada praktikum percobaan oersted dan kemagnetan bumi yang menggunakan kompas yang sama. Pada percobaan Oersted, bentuk kompas yang dapat bergerak bebas menyebabkan pergerakan kompas cenderung vertikal sehingga pergerakan menyimpan secara horizontal pada kompas tidak terlihat jelas. Evaluasi dari permasalahan tersebut dengan menyediakan magnet yang lain untuk percobaan Oersted dengan gantungan yang berbeda yang memungkinkan kompas hanya bergerak horizontal.

Pada kategori petunjuk penggunaan media baik pada buku pedoman maupun 
petunjuk kerja pada LKS, $43 \%$ siswamenyatakan setuju sedangkan 57 \%siswa menyatakan tidak setuju.Munculnya penilaian tersebut karena banyak petunjuk kerja yang tidak jelas baik pada struktur gambar maupun pada gambar yang menyebabkan siswa sering bertanya kepada guru karena tidak memahami perintah yang ada pada LKS.

Pada aspek dengan media $\mathrm{MKB}$, materi pembelajaran yang berisi konsep-konsep kemagnetan lebih mudah dipahami, $14 \%$ siswamenyatakan sangat setuju, 72 \%siswa menyatakan setuju dan $14 \%$ siswa menyatakan tidak setuju. Munculnya anggapan tersebut karena tidak adanya tanda keterangan kutub magnet pada ujung magnet batang. Tidak dicantumkannya jenis magnet tersebut karena magnet batang terbentuk secara elektromagnet sehingga untuk memahami jenis kutubnya harus menggunakan kaidah tangan kanan. Adanya fitur pengubah polaritas menjadi alasan tersendiri tidak dicantumkannya tanda kutub magnet tersebut karena jenis kutub magnet dapat berubahubah tergantung jenis polaritas tegangan dari adaptor. Solusi dari permasalahan tersebut dengan membuat simbol kutub magnet pada magnet batang dan memberikan keterangan pada pengubah polaritas tegangan tentang kutub positif dan negatif. Solusi yang lain dengan menjadikan pembelajaran membuat magnet secara elektromagnet pada pertemuan pertama agar siswa dapat mengetahui jenis kutub magnet yang terbentuk setelah memahami aturan tangan kanan.

Pada aspek memahami materi-materi yang bersifat abstrak (tidak nyata) menjadi lebih mudah dipahami setelah menggunakan media MKB. Munculnya penilaian tersebut karena kelemahan adaptor yang mudah cepat panas sehingga dalam setiap melakukan penelitian 3-4 menit harus segera dimatikan untuk mendinginkan transformator. Hal ini berimplikasi pada praktikum percobaan Oersted yang memiliki hambatan pengganti paling kecil dari jenis praktikum yang ada. Hambatan yang besarnya hampir nol cukup mengganggu siswa karena tidak dapat melakukan eksperimen secara lebih mendetail. Demikian juga dengan magnet batang yang dililiti kawat dengan diameter $5 \mathrm{~mm}$. Hambatan pengganti yang sangat kecil akan menghasilkan arus dan tidak dapat ditahan oleh kawat penghantar karena memiliki penampang yang besar. Permasalahantersebut diatasi dengan mengganti adaptor yang semula 2 Amper menjadi 3 amper untuk memperbesar arus yang dihasilkan. Solusi lain adalah dengan mengganti jenis kawat lilitan dari $0.5 \mathrm{~mm}$ menjadi $0.3 \mathrm{~mm}$ dan $0.2 \mathrm{~mm}$ agar kawat penghantar dapat menahan besarnya arus yang mengalirinya.

Pada aspek media MKB memberikan kesempatan yang luas untuk mencoba melakukan analisa dan membuat perkiraan/hipotesis $71 \%$ siswamenyatakan setuju dan 27 
$\%$ siswamenyatakan tidak setuju. Hal ini disebabkan faktor adaptor yang menjadi power supply bagi media MKB tidak mampu bertahan dalam waktu yang lama untuk memberikan kenyamanan pada siswa dalam melakukan praktikum.

Hasil respons siswa pada tahap uji coba skala terbatas dipergunakan sebagai dasar untuk mengevaluasi dan memperbaiki media MKB yang dikembangkan dengan ditekankan pada penilaian siswa yang dianggap rendah. Hasil evaluasi media MKB selanjutnya diuji coba pada skala lebih luas.

Respon siswa pada tahap uji coba pasa skala luas diperoleh dengan melibatkan 20 siswa di SMPN 3 Lingsar. Respon siswa pada skala lebih luas ditampilkan pada tabel 3.

Tabel 3: Tanggapan siswa terhadap media MKB pada Uji coba skala lebih luas.

\begin{tabular}{|l|l|l|l|l|}
\hline \multicolumn{2}{|c|}{ PERNYATAAN } & \multicolumn{3}{c|}{ SKOR } \\
\cline { 2 - 5 } & \multicolumn{1}{|c|}{ SS } & \multicolumn{1}{c|}{ S } & \multicolumn{2}{c|}{ STS } \\
\hline Belajar sains fisika dengan media tiga dimensi MKB menyenangkan & 16 & 4 & 0 & 0 \\
\hline Media MKB cukup menarik & 9 & 11 & 0 & 0 \\
\hline Media MKB mudah digunakan & 8 & 12 & 0 & 0 \\
\hline Petunjukkan penggunaan media MKB mudah dipahami & 13 & 4 & 3 & 0 \\
\hline $\begin{array}{l}\text { Dengan media MKB, materi pembelajaran yang berisi konsep-konsep } \\
\text { kemagnetan lebih mudah dipahami }\end{array}$ & 9 & 11 & 0 & 0 \\
\hline $\begin{array}{l}\text { Dengan media MKB, kaidah dan hukum fisika yang berkaitan dengan } \\
\text { kemagnetan mudah dipahami }\end{array}$ & 13 & 6 & 1 & 0 \\
\hline $\begin{array}{l}\text { Pembelajaran sains dengan media MKB mendorong rasa ingin tahu } \\
\text { siswa }\end{array}$ & 11 & 9 & 0 & 0 \\
\hline $\begin{array}{l}\text { Memahami materi-materi yang bersifat abstrak (tidak nyata) menjadi } \\
\text { lebih mudah dipahami setelah menggunakan media MKB. }\end{array}$ & 10 & 9 & 1 & 0 \\
\hline $\begin{array}{l}\text { Media MKB memberikan kesempatan yang luas untuk mencoba } \\
\text { melakukan analisa dan membuat perkiraan/hipotesis }\end{array}$ & 7 & 11 & 2 & 0 \\
\hline $\begin{array}{l}\text { Wawasan tentang kemagnetan menjadi bertambah luas sejak } \\
\text { pembelajaran dengan media MKB. }\end{array}$ & 15 & 5 & 0 & 0 \\
\hline
\end{tabular}

Dari tabel 3 diketahui beberapa aspek pada uji coba skala terbatas mengalami peningkatan respon dari siswa pada uji coba skala lebih luas. Pada aspek media MKB mudah digunakan didapatkan $40 \%$ siswa menyatakan sangat setuju dan $60 \%$ siswa menyatakan setuju. Penilaian siswa ini didapatkan setelah menambahkan kompas untuk percobaan Oersted yang hanya dapat bergerak horizontal sehingga dapat ditempatkan lebih dekat dengan kawat penghantar sehingga pengaruh medan magnet yang dihasilkan lebih mendapat respon dengan menyimpangnya magnet jarum dari posisi semula. Respon tersebut akan lebih jelas difahami siswa dengan mengubah arah polaritas tegangan dan melakukannya secara berulang.

Dari aspek petunjukkan penggunaan media MKB mudah dipahami, 65\% siswa memberikan respon sangat setuju, $20 \%$ siswa menilai setuju dan $15 \%$ siswa menyatakan 
tidak setuju. Penilaian tersebut disebabkan masih adanya bagian LKS yang menjadi petunjuk siswa dalam melakukan praktikum masih sulit difahami siswa meskipun sudah dilakukan perbaikan sebelumnya.

Pada aspek dengan media MKB, materi pembelajaran yang berisi konsep-konsep kemagnetan lebih mudah dipahami, $65 \%$ siswa menyatakan sangatn setuju, $30 \%$ siswa menyatakan setuju dan $5 \%$ siswa menyatakan tidak setuju. Meskipun sudah mendapatkan perbaikan dengan memberikan label kutub magnet dan kutub tegangan pada pada magnet batang dan polaritas tegangan, tetapipeneliti beranggapan masih ada siswa yang kesulitan dalam menerjemahkan jenis kutub magnet ketika terjadi perubahan polaritas tegangan pada media.

Pada aspek memahami materi-materi yang bersifat abstrak (tidak nyata) menjadi lebih mudah dipahami setelah menggunakan media MKB, $50 \%$ siswa menyatakan sangat mendukung, $45 \%$ siswa menyatakan mendukung dan $5 \%$ siswa menyatakan tidak mendukung. Setelah dilakukan perbaikan mengganti adaptor menjadi 3 A dan mengganti lillitan dengan diameter penampang 0,3 dan $0,2 \mathrm{~mm}$ pada magnet batang, arus yang melalui adaptor tidak sebesar sebelumnya dengan penampang $0,5 \mathrm{~mm}$ sehingga adaptor dapat lebih lama digunakan selama percobaan. Penggantian kawat penghantar pada magnet batang dengan penampang lebih kecil dengan tujuan mengurangi besar arus yang mengalir berdampak berakibat pada suhu magnet batang yang menghangat. Hal ini cukup mengganggu konsentrasi siswa ketika memegang magnet tersebut dalam melakukan percobaan.

Pada aspek Media MKB memberikan kesempatan yang luas untuk mencoba melakukan analisa dan membuat perkiraan/hipotesis $35 \%$ siswa menyatakan sangat setuju, $55 \%$ siswa menyatakan setuju dan $10 \%$ siswa menyatakan tidak setuju. Munculnya penilaian tersebut karena masih terbatasnya waktu siswa dalam melakukan pengulangan pada percobaan-percobaan dan dalam waktu yang lebih lama. Meskipun adaptor sudah diganti dengan $3 \mathrm{~A}$, periode pelaksanaan tiap mata praktikum hanya bertambah sekitar 2 menit. Terlebih pada percobaan Oersted yang dapat bertambah sekitar 1,5 menit.Hal ini disebabkan rendahnya hambatan pengganti dari kawat penghantar baik pada induktor pada lilitan maupun konduktor pada percobaan Oersted.

\section{Kesimpulan}

Media MKB dapat digunakan pada pembelajaran kemagnetan yang secara garis besar terbagi menjadi menjadi 4 yaitu: (1) Menginformasikan cara membuat magnet 
dengan menggosok dan induksi dan menentukan jenis tiap kutubnya, (2) Menginformasikan cara membuat magnet dengan elektromaget dan menentukan tiap kutubnya. (3) Menginformasikan konsep inklinasi dan deklinasi pada kemagnetan bumi, dan (4) Manginformasikan posisi magnet jarum pada percobaan Oersted.

Siswa memberikan tanggapan dengan kriteria baik terhadap pengembangan media MKB. Karena baik dari segi desain, user friendly, mudah mendapatkan pemahaman dan penambahan wawasan yang bauk bagi siswa.

\section{Daftar Pustaka}

Djamarah. 2002. Teori Motivasi. edisi 2 Jakarta : PT. Bumi Aksara

Emzir. 2010. Metodologi Penelitian Pendidikan Kuantitatif dan Kualitatif. Jakarta. PT. Rajagrafindo Persada

Fajarudin, Mukhammad Fauji. 2012. Pengaruh Model Pembelajaran Inkuiri Terbimbing Berbantuan Website Terhadap Peningkatan Penguasaan Konsep dan Kemampuan Pemecahan Masalah Siswa Kelas X Pada Topik Listrik Arus Searah. Tesis Universitas Pendidikan Bandung. Dapat diakses melalui http://repository.upi.edu/tesislist.php Tanggal Akses 27 November 2012

Gall G, Gall J, and Borg W. 2003. Educational Research. An Intruduction. Sevent Edition. New York : Pearson Education, Inc.

Gunawan. 2011. Model Laboratorium Virtual Fisika Modern Untuk Meningkatkan Keterampilan Generik Sains Mahasis. Jurnal Pijar MIPA, Universitas Mataram, Vol.VI, No. 2 September 2011, Ha.39-44.

Hassard, J,. \& Dias, M. 2009. The Art of Teaching Science. London: Oxford University Press.

Heinich, R., Molenda, M., Smaldino, S.E.,\& Russel, J.D. 2002. Instructional Technologi and Media for Learning. Ohio:Pearson.

Sukmadinata, NS, 2010. Metode Penelitian Pendidikan. Bandung. Rosda

Widoyoko, S.E.P. 2012.Teknik Penyusunan Instrumen Penelitian. Yogyakarta : Pustaka Pelajar 